\title{
Disability and Disaster
}

Ashok Hans

$\underline{\&}$

$\underline{\text { Nizni Hans }}$

Introduction

In recent years many natural and man made disasters have struck regions across the globe. The disasters of the last few years, for instance, the Tsunami that devastated regions from South East Asia to Africa, was followed by Katrina which hit the United States and an Earthquake struck Kashmir in India and Pakistan soon after it. From our experiences in these disasters we have come to realize that they affect most, the vulnerable of groups in the community amongst them the women, children, elderly and the disabled (IDRM, 2005; Kitts et al IDDC, 2005). It is important to note initially, that Disasters have an impact on disability, by disproportionately affecting persons with existing disabilities as well as generating disabilities in people who did not have disability earlier.

This paper attempts to focus on one category of the vulnerable the disabled, as very little attention has been paid to them. The paper will also trace the few attempts made to highlight the issue in the last few years and the recommendations that have come from these exercises.

In regions of the world where poverty is already an issue and disabled rarely access available resources even in normal times, the issue attains more criticality. Health for instance being one of the major impeding factors during a disaster is difficult to address in poor developing countries as disasters demand emergency services on a large scale. The inability of most of these countries to cope is not only an issue related to lack of finances but also of trained manpower. Some countries have crossed these hurdles for instance Bangladesh has a system in place, but even here the disabled have been left out though attempts are being made for their inclusion (DER, 2005). It has come to be universally recognized that under emergency situations disability rights are ignored as they are invisible as a group with very little voice ${ }^{1}$.

\section{Why Include Disability in Disasters}

Earlier works as cited above have shown that Disability rights are not protected during disasters. Judy Huemann, the Disability and Development Advisor to the World Bank while video-addressing the participants of a Satellite Meeting on Inclusion of Disability in Disaster Response in Mumbai on $17^{\text {th }}$ December 2005 organized by the authors at Forum 9 of the Global Health Research Forum recounted that after the Tsunami struck, Global Partnership for Disability and Development sent a questionnaire concerning the effect of Tsunami on disabled individuals ${ }^{2}$. As a result, two reports one from CIR, (Centre for International Rehabilitation) and the other from IDDC (International Disability and Development Consortium) were produced. Maria Veronica Reina, and 
Anne Hayes of the Center for International Rehabilitation (CIR) who also joined in the video discussion stated that the reports had highlighted the facts that

- It had been difficult to know the exact number of people with disabilities, who were injured or killed by Tsunami.

- It had also been difficult to find available statistics on the number of people who would have a permanent disability as a result of the Tsunami.

- Disabled people were not included in existing emergency plans in these countries.

- Disabled people were also excluded from the co-ordination meeting that took place among the international NGOs relief agencies and Government officials

The participants of the Satellite meeting in Mumbai agreed that to protect the rights of the disabled Standards are important to deal with the situation. They advanced the view, that there is a need to address issues at two levels: 1) Issues specific to disasters and 2) Issues related to the structural changes required to reduce disability among people living with impairments of any kind including in disaster regions.

In this context it was felt by the participants that attempts should be made to promote the inclusion and active involvement of disabled persons in the governance of general health and emergency/conflict response and create a system whereby collaboration between key stakeholders (DPOs, Governments, UN, donors, NGOs etc) actively considers disability issues during disasters to assure the health, safety and other human rights of disabled people. This would mean providing a set of policy guidelines or principles to stakeholders in the region (Governments, NGOs, etc.) to follow during disasters which would include among others measures to:

a. Ensure that warning systems are disability-friendly, i.e. meet universal design principles.

b. Ensure that disability organizations are actively involved with disaster relief organizations and governments in the overall governance of response coordination offices during disasters.

c. Ensure that relief workers understand and are sensitive to disability issues in working with people.

d. Ensure that universal design principles are met in facilities housing services for disaster relief to ensure that they are disability-friendly and accessible for the many more people becoming impaired during disasters and for disabled people already living in disaster-affected countries.

e. Medical and epidemiological monitoring of internally displaced people, including elaboration of a data base of people directly affected by the disaster due to respiratory infection, wounds and injuries resulting in impairment, and of disabled people whose health and well-being may be put at risk during and post disaster.

f. Support to medical services and to local groups, with priority given to ensuring access to supports and services for people whose health and wellbeing is particularly at risk during these times (disabled people, pregnant women, very young and very old people, orphans). 
g. Create a "level playing field" by providing funding for the active participation of members of the disability community in governance, including for attendance at meetings and policy making initiatives at all levels, to ensure that their right to participate is not violated.

Thus it was concluded that among other things it could be done by exploring ways on how to grow "voice" in a way that is credible and empowering and to carry out research which would effect social change and construct new inclusive, equalityseeking structures.

In June 2006 the World Bank sponsored an ediscussion on the subject in which more than 500 persons participated the conclusions drawn were similar to the Mumbai meeting ${ }^{3}$. There were some added issues discussed in detail such as technology. Regarding this issue participants felt that though technology is important people have already realized that technology is vastly overrated in catastrophic circumstances for even when the US Government agencies realized the probability of the massive tsunami, they could reach very few people by internet, radio, phone or otherwise; and few warning devices were in place, even if they could have reached local emergency officials or agencies). The three main reasons why new technology available is not practical were identified as :

1. Remote location and difficult terrain

2. Essential services that most of us take for granted not being available.

3. Indifference by some local authorities to prepare a universal plan and unwillingness to train and work with volunteers.

4. In this context besides new technology appropriate technology needs to be provided.

\section{Conclusions}

From the above it is quite clear that we still need to carry out advocacy and research on many issues related to the disabled so that their inclusion during disasters becomes easier. These efforts would assist to disseminate information to Aid workers and funding agencies, government officials in charge of policy making and formation of Standards at all levels ${ }^{4}$. It is important to start a dialogue with all stake holders and the disabled so that justice will no longer be denied

\section{Notes}

1. In 1999 when the a super cyclone struck the east coast of India killing thousands and devastating the region, agencies from all over the world under the Coordination of the UNDP poured in aid but despite attempts by the author's organization SMRC disability was completely left out of all activities. The same has been noticed in all recent disasters except in Kashmir (On the Pakistan side) where some steps were taken by the World Bank and Handicap International to include the disabled. 
2. A workshop was organized on "Setting International Standards for the Inclusion of Disability in Disaster Response" by the Shanta Memorial Rehabilitation Centre, India in collaboration with the Global Forum for Health Research, Geneva, Switzerland held in Mumbai, India on 17th September 2005, as a satellite meeting to Forum 9 where Mary Anne Burke from the Forum assisted in conducting the meeting. Participants included disabled activists, UN officials, Academics and Global Forum members. For details on the Mumbai Proceedings see www.smrcbbsr.org.

3. The ediscussion was in three parts (World Bank.2006):

Week 1 May 22- May 26: Disaster Preparedness \& Mitigation, Moderated by Maria Veronica Reina and Anne Hayes;

Week 2 May 29- June 6: Emergency Response / Relief moderated by Moira Jones and Ashok Hans;

Week 3 June 5- June 9: Short/Medium Term Social-Economic Recovery \& Reconstruction by Maria Kett.

4. Inclusion of issues in international instruments and policies could start with the International Convention on the Rights of Disabled Persons, Articles 10 (Right to Life) and 11 (Situations of Risk)

\section{References}

DER. 2005 .

http://www.lcgbangladesh.org/DER/reports/G\&D\%20Workshop\%20Summary\%2014\%2 0Aug\%2005.pdf)

IDRM. 2005. IDRM: Disability and Early Tsunami Relief Efforts in India, Indonesia and Thailand

Kett, Sue Stubbs and Rebecca Yeo. 2005 IDDC Research Report: Disability in Conflict and Emergency Situations: Focus on Tsunami - affected Areas University of East Anglia

World Bank. 2006. http://www.dgroups.org/groups/worldbank/Disaster-Disability. 
